\title{
Mid- to long-term rates of symptomatic adjacent-level disease requiring surgery after cervical total disc replacement compared with anterior cervical discectomy and fusion: a meta-analysis of prospective randomized clinical trials
}

Yifei Deng ${ }^{1 \dagger}$, Guangzhou $\mathrm{Li}^{2+}$, Hao Liu ${ }^{1 *}$, Ying Hong ${ }^{3 *}$ and Yang Meng ${ }^{1}$

\begin{abstract}
Background: Thus far, no meta-analysis focusing on the mid- to long-term incidence of adjacent segment disease requiring surgery after cervical total disc replacement and anterior cervical discectomy and fusion has been published yet. This study aimed to compare mid- to long-term rates of symptomatic adjacent-level disease requiring surgery after cervical disc replacement and anterior cervical fusion.

Methods: A meta-analysis was performed, and only randomized controlled trials with a follow-up period of more than 48 months reporting rates of symptomatic adjacent-level disease requiring surgery after cervical total disc replacement and anterior cervical discectomy and fusion were included.

Results: The analysis revealed that the overall rate of symptomatic adjacent-level disease requiring surgery in the cervical disc replacement group was significantly lower than that of the anterior cervical fusion group at 48-120 months' follow-up. The subgroup analysis of different follow-up periods also yielded the same results. The rate of symptomatic adjacent-level disease requiring surgery in the cervical disc replacement group using unrestricted prosthesis was significantly lower than that of the anterior cervical fusion group $(p<0.001)$; however, the cervical disc replacement group using semi-restricted prosthesis showed no statistical difference compared with the fusion group.

(Continued on next page)
\end{abstract}

\footnotetext{
*Correspondence: dr.liuhao6304@yahoo.com; hongying518@163.com

${ }^{\dagger}$ Yifei Deng and Guangzhou Li contributed equally to this work and should

be considered co-first authors.

'Department of Orthopedic Surgery, West China Hospital, Sichuan University,

No. 37 Guo Xue Xiang, Chengdu 610041, Sichuan, China

${ }^{3}$ Department of Anesthesia and Operation Center/West China School of

Nursing, West China Hospital, Sichuan University, No. 37 Guo Xue Xiang,

Chengdu 610041, Sichuan, China

Full list of author information is available at the end of the article
}

(c) The Author(s). 2020 Open Access This article is licensed under a Creative Commons Attribution 4.0 International License, which permits use, sharing, adaptation, distribution and reproduction in any medium or format, as long as you give appropriate credit to the original author(s) and the source, provide a link to the Creative Commons licence, and indicate if changes were made. The images or other third party material in this article are included in the article's Creative Commons licence, unless indicated otherwise in a credit line to the material. If material is not included in the article's Creative Commons licence and your intended use is not permitted by statutory regulation or exceeds the permitted use, you will need to obtain permission directly from the copyright holder. To view a copy of this licence, visit http://creativecommons.org/licenses/by/4.0/ The Creative Commons Public Domain Dedication waiver (http://creativecommons.org/publicdomain/zero/1.0/) applies to the data made available in this article, unless otherwise stated in a credit line to the data. 


\begin{abstract}
(Continued from previous page)
Conclusions: Our review suggests that cervical disc replacement is preferable to anterior cervical fusion in reducing the incidence of symptomatic adjacent-level disease requiring surgery at mid- to long-term follow-up. A review of the literature also demonstrated that randomized controlled trials investigating the rate of symptomatic adjacentlevel disease requiring surgery were insufficient; therefore, studies focusing on this subject with longer-term followup are warranted.
\end{abstract}

Keywords: Adjacent segment disease, Cervical total disc replacement, Anterior cervical discectomy and fusion

\section{Background}

Anterior cervical discectomy and fusion (ACDF) has a long history of successfully treating cervical spondylotic disease and other cervical pathologies, and at present, it is still regarded as a relatively safe and effective treatment option [1-3]. However, ACDF is associated with potential concerns, and one overarching concern is the development of symptomatic adjacent segment disease (ASD) after surgery. Fusion techniques result in altered biomechanics of the cervical spine and potentially accelerate the degenerative process at adjacent segments, which may be one of the primary causes of ASD $[4,5]$. ASD was reported to occur at a rate of $2.9 \%$ annually in patients who underwent ACDF, with approximately $25.6 \%$ of patients predicted to develop symptomatic ASD within 10 years in a landmark study by Hilibrand et al. $[1,5]$. Lee et al. performed a large retrospective study and reported similar results [6]. In an effort to address this concern, a variety of non-fusion or motionpreserving techniques, such as cervical total disc replacement (TDR), have been introduced and proposed as an alternative treatment option to $\operatorname{ACDF}[1,3,7]$.

The early to mid-term clinical outcomes after cervical TDR are better than or non-inferior to that of ACDF; however, there remains controversy with regard to TDR decreasing the rate of ASD development [1, 7-9]. It is reasonable to address such controversy by comparing the rates of ASD development after cervical TDR and ACDF based on mid- to long-term data, since it is too early to observe degenerative changes secondary to altered biomechanics of the non-fused or fused cervical spine using early- to mid-term data [10]. Recently, several 7- to 10-year data from the US Food and Drug Administration investigational device exemption randomized controlled trial (RCT) studies have been published, rendering the analysis of mid- to long-term rates of ASD development after cervical TDR possible [11-13]. However, due to the lack of established standardized criteria, the application of different criteria in studies investigating ASD might be another reason why investigators could not arrive at the same conclusion [14]. Meanwhile, ASD was the most frequent indication for surgery at the adjacent level after TDR and ACDF, but it was not the only indication, since neck pain or revision surgery at the index surgical level might also be considered as such [15-17]. Hence, based on these factors, several meta-analyses reviewing RCTs failed to resolve the issue [10, 18-23]. Consequently, the incidence rate of symptomatic adjacent-level disease requiring surgery (SALDRS) might be a more objective parameter than that of ASD. To date, no meta-analysis focusing on the mid- to long-term incidence of SALDRS after TDR compared with ACDF has been published yet. Thus, this meta-analysis was performed with the aim of comparing mid- to long-term SALDRS rates between TDR and ACDF for the first time.

\section{Methods}

This meta-analysis was conducted in accordance with the PRISMA statement [24].

\section{Search strategy}

PubMed and Embase (updated until July 1, 2019) were searched exhaustively using a combination of the following terms: ("arthroplasty" [title/abstract] OR "replacement" [title/abstract] OR "arthrodesis" [title/abstract] OR "prosthesis" [title/abstract]) AND "cervical" [title/abstract] AND "fusion" [title/abstract]. No language restrictions were applied. We also reviewed the reference lists of relevant studies to search for potentially relevant studies. Repetition of studies was identified according to the study information (such as hospitals and study period). Only the largest one among the studies with patient overlap could be retained.

\section{Inclusion and exclusion criteria}

The inclusion criteria were as follows: (1) RCTs, (2) medically confirmed degenerative cervical spine disease requiring surgical intervention, (3) studies comparing the postoperative incidence of SALDRS between ACDF and TDR, and (4) studies with a follow-up period of > 48 months.

The exclusion criteria were as follows: (1) studies that did not report the incidence of SALDRS in both the ACDF and TDR groups; (2) unrelated research studies; (3) literature reviews or meta-analyses, biomechanical studies, case reports, letters, and conference abstracts; (4) prospective non-randomized studies and 
retrospective studies; and (5) studies reporting the incidence of SALDRS with the same follow-up period as that of studies in which patient overlap occurred.

\section{Data extraction}

The following required data were extracted independently by two authors: author, year of publication, country, study design, number of patients, follow-up period, and SALDRS. Any discrepancies in the data extracted by the two authors were resolved by a discussion with the third author.

\section{Risk of bias assessment}

To evaluate the quality of the included RCTs, two authors independently evaluated the risk of bias of eligible studies according to the Cochrane Back Review Group Guideline [25]. Any disagreement between the two reviewers would be discussed with the third author to achieve consensus. The items included in the risk of bias assessment were as follows: random sequence generation, allocation concealment, blinding of participants and personnel, blinding of outcome assessment, incomplete outcome data, selective reporting, similarity of baseline indicators, and other biases. Each item was classified as having a low risk of bias, an unclear risk of bias, or a high risk of bias. If at least $50 \%$ of the items indicated a "low risk of bias" in one article, then this article would be considered to have a "low risk of bias." Otherwise, this article would be considered to have a "high risk of bias."

\section{Statistical analysis}

This meta-analysis was conducted using Review Manager software 5.3 (RevMan 5.3, Cochrane Collaboration). The risk ratio (RR) and 95\% confidence interval (CI) were assessed for dichotomous data (SALDRS). $p$ values $<0.05$ were considered statistically significant. Begg's and Egger's tests were performed using STATA 13.0 (StataCorp., TX, USA) to evaluate publication bias when more than 10 studies were included in a meta-analysis. Moreover, trim-and-fill analysis was also conducted to investigate possible publication bias. The $I^{2}$ statistic (ranging from 0 to $100 \%$ ) was used to evaluate the heterogeneity among the included studies. A $p$ value $<0.10$ was considered statistically significant. An $I^{2}$ statistic $>$ $50 \%$ was considered to indicate obvious heterogeneity. A random-effect analysis was performed when the $p$ value of the chi-square test was $<0.10$ or when the $I^{2}$ statistic was $>50 \%$. Otherwise, a fixed-effect analysis was performed. Sensitivity analysis was also conducted to examine the included studies individually. It could be beneficial to explain the reason for the high heterogeneity and analyze the effect of one study on the overall result.

\section{Results}

Identification of the included studies

A total of 2745 studies were identified by searching PubMed $(n=1118)$ and Embase $(n=1627)$. Due to duplication, 1064 studies were removed, and 1681 studies were retained. In total, 48 case reports, 47 commentaries or letters, 321 conference abstracts, 23 hybrid surgery studies, 262 literature reviews, 502 unrelated studies, 15 animal studies, 5 questionnaire studies, and 67 biomechanical studies were excluded after assessing the title and abstract. Overall, 147 studies not reporting both ACDF and TDR, 92 retrospective studies, 64 non-randomized prospective studies, 3 study protocols, 55 RCTs with a follow-up period of less than 48 months, and 18 RCTs with a follow-up period of more than 48 months not reporting SALDRS data were excluded after the assessment of full-text articles. There were 12 articles reporting SALDRS data of both the ACDF and TDR groups at 4 years' follow-up [26-28], 5 years' follow-up [29-33], 7 years' follow-up [34-36], 9 years' follow-up, and 10 years' follow-up [36, 37]. Only two studies reported data at 4 years' follow-up, and the follow-up period was close to each other, i.e., between 4 and 5 years. Therefore, the data of studies with 4 and 5 years' follow-up were combined. Two articles were excluded due to patient overlap $[27,28]$. One study [33] was excluded because of patient overlap and non-randomization of some patients in the TDR group. Some studies with patient overlap that reported data at different follow-up periods were included in the subgroup analysis [26,31]. Ultimately, 9 articles (8 RCTs) were included in the meta-analysis. A flow diagram of the literature search strategy for relevant studies is shown in Fig. 1.

\section{Characteristics of the included studies}

There were 9 articles ( 8 RCTs) included in the metaanalysis. The basic characteristics of the included studies are presented in Table 1. A total of 2395 patients in 8 RCTs were included in the meta-analysis. There were 1334 patients treated with TDR and 1061 patients treated with ACDF.

\section{Risk of bias assessment}

According to the Cochrane Back Review Group Guideline [25], all 9 articles were considered to have a low risk of bias (Fig. 2). The majority of studies did not mention allocation concealment and blinding of participants, personnel, and outcome assessment. It was difficult to blind the participants and personnel in studies involving surgical procedures. Most studies showed a high risk of bias in incomplete outcome data. A follow-up rate of over $80 \%$ in both groups was observed in only two studies. This study was not eligible for publication bias 




Fig. 1 Flow diagram of the study selection assessment because only 8 RCTs were included in the meta-analysis.

\section{Meta-analysis of SALDRS}

Eight studies consisting of 1334 patients in the TDR group and 1061 patients in the ACDF group were included in the meta-analysis. The overall SALDRS rate of the TDR group was significantly lower than that of the ACDF group (RR 0.38, 95\% CI [0.27, 0.53], $p=0.12, I^{2}=$ $39 \%$, Fig. 3). The heterogeneity was not significant, and the result was reliable. This heterogeneity was attributed to the study by Phillips et al. [34], according to the sensitivity analysis. The SALDRS rate of the TDR group was $0.4 \%(1 / 218)$, while that of the ACDF group was $10.2 \%$ $(19 / 185)$. When the study by Phillips et al. [34] was excluded, the result remained the same (RR 0.46, 95\% CI $[0.32,0.65], p=0.50, I^{2}=0 \%$ ); however, the heterogeneity was lower. This resulted from their unique patient inclusion criteria, in which approximately 12\% (29 TDR and 20 ACDF) of the 218 TDR and 185 ACDF patients had prior adjacent or nonadjacent single-level fusions, and the SALDRS rates in the TDR group and ACDF group were theoretically different from those of other RCTs.

Five studies with 620 patients in the TDR group and 529 patients in the ACDF group were included in the meta-analysis of the SALDRS rate at 4-5 years' followup. The SALDRS rate of the TDR group was significantly lower than that of the ACDF group (RR 0.37, 95\% CI $[0.21,0.67], p=0.65, I^{2}=0 \%$, Fig. 4). The results were considered reliable.

Data on the SALDRS rate at 7 years' follow-up were collected from 4 studies. There were 1125 patients and 857 patients in the TDR and ACDF groups, respectively. The SALDRS rate of the TDR group was significantly lower than that of the ACDF group (RR 0.36, 95\% CI $[0.16,0.80], p=0.04, I^{2}=64 \%$, Fig. 5). The heterogeneity

Table 1 Basic characteristic of the studies included in the meta-analysis

\begin{tabular}{|c|c|c|c|c|c|c|c|c|c|}
\hline \multirow[t]{2}{*}{ Study } & \multirow{2}{*}{$\begin{array}{l}\text { Study } \\
\text { design }\end{array}$} & \multicolumn{2}{|c|}{ Sample size } & \multirow{2}{*}{$\begin{array}{l}\text { Follow-up } \\
\text { time }\end{array}$} & \multirow[t]{2}{*}{ Prosthesis } & \multirow{2}{*}{$\begin{array}{l}\text { Operative } \\
\text { level }\end{array}$} & \multicolumn{2}{|c|}{ Follow-up rate } & \multirow{2}{*}{$\begin{array}{l}\text { Study } \\
\text { center }\end{array}$} \\
\hline & & TDR & ACDF & & & & TDR & ACDF & \\
\hline Garrido et al. (2010) [24] & $\mathrm{RCT}$ & 21 & 26 & 48 months & Bryan & 1 & $85.7 \%$ & $76.9 \%$ & Single \\
\hline Burkus et al. (2010) [28] & $\mathrm{RCT}$ & 276 & 265 & 60 months & Prestige ST & 1 & $52.2 \%$ & $47.9 \%$ & Multiple \\
\hline Delamarter et al. (2013) [27] & $\mathrm{RCT}$ & 103 & 106 & 60 months & Prodisc C & 1 & $72.7 \%$ & $63.5 \%$ & Multiple \\
\hline Phillips et al. (2015) [32] & $\mathrm{RCT}$ & 218 & 185 & 84 months & PCM & 1 & $31.2 \%$ & $22.7 \%$ & Multiple \\
\hline Hou et al. (2016) [30] & $\mathrm{RCT}$ & 56 & 51 & 61 months & Mobi-C & 1 & $91.1 \%$ & $94.1 \%$ & Single \\
\hline Hisey et al. (2016) [29] & $\mathrm{RCT}$ & 164 & 81 & 60 months & Mobi-C & 1 & $85.5 \%$ & $78.9 \%$ & Multiple \\
\hline Donk et al. (2017) & $\mathrm{RCT}$ & 50 & 47 & $8.9 \pm 1.9$ years & Bryan & 1 & $98.0 \%$ & $97.9 \%$ & Single \\
\hline \multirow[t]{2}{*}{ Radcliff et al. (2017) [33] } & $\mathrm{RCT}$ & 164 & 81 & 84 months & Mobi-C & 1 & $80.1 \%$ & $74.3 \%$ & Multiple \\
\hline & $\mathrm{RCT}$ & 225 & 105 & 84 months & Mobi-C & 2 & $84.4 \%$ & $75.0 \%$ & Multiple \\
\hline \multirow[t]{2}{*}{ Ghobrial et al. (2018) [34] } & $\mathrm{RCT}$ & 518 & 486 & 84 months & Bryan/Prestige ST & 1 & Not specified & Not specified & Mutiple \\
\hline & $\mathrm{RCT}$ & 242 & 221 & 120 months & Bryan & 1 & $53.7 \%$ & $46.6 \%$ & Mutiple \\
\hline
\end{tabular}




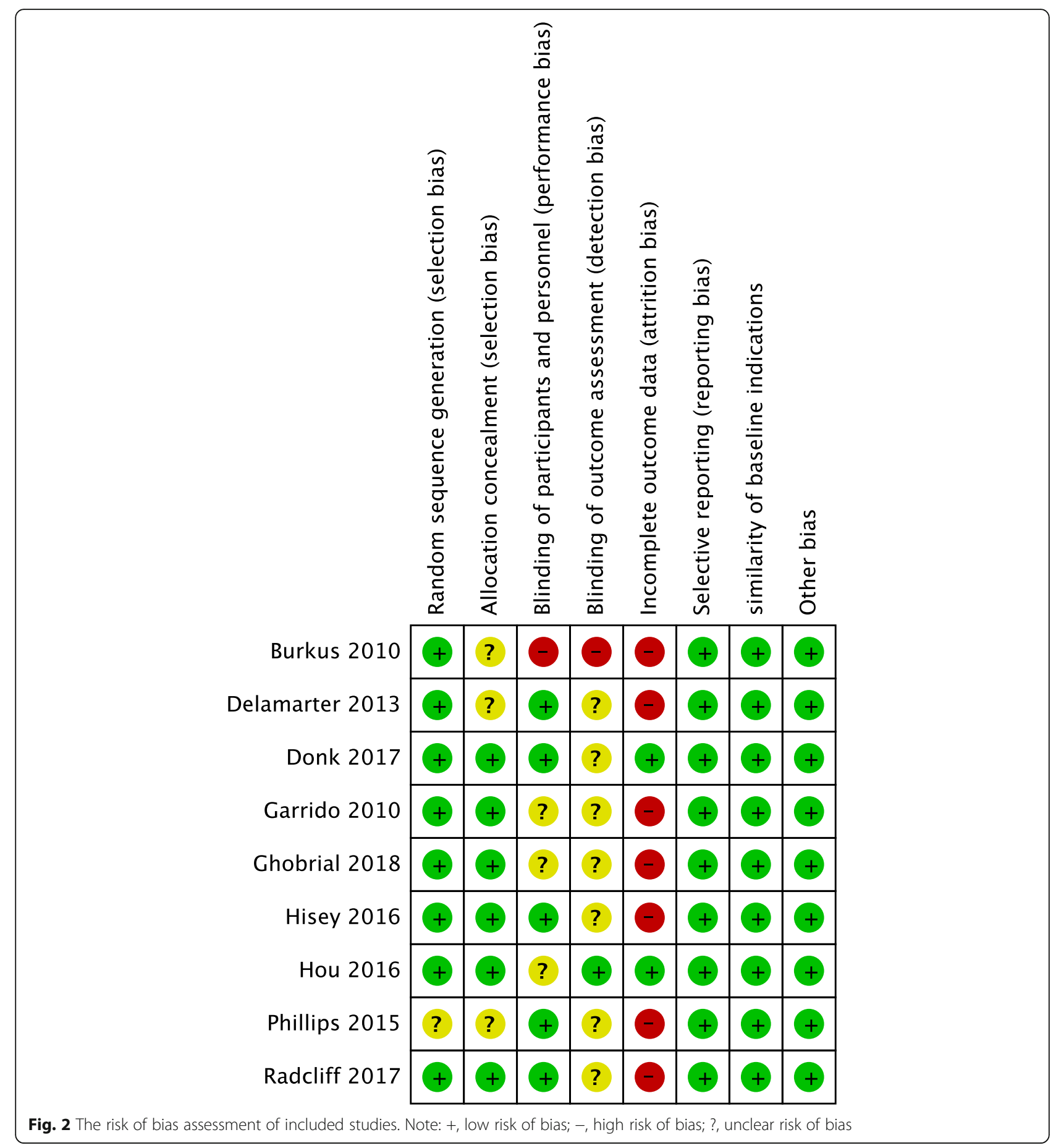

was significant, which was attributed to the study by Phillips et al. [34], according to the sensitivity analysis.

Two studies consisting of 292 patients and 268 patients in the TDR group and ACDF group, respectively, were included in the meta-analysis of SALDRS rate at 9-10 years' follow-up. The SALDRS rate of the TDR group was significantly lower than that of the ACDF group (RR 0.53, 95\% CI [0.33, 0.86], $p=0.18, I^{2}=44 \%$,
Fig. 6). $I^{2}$ was $44 \%$, which may be caused by the small number of included studies and patients.

Data on the SALDRS rate of the groups with semirestricted prosthesis were collected from 3 studies. There were 597 patients and 556 patients in the TDR and ACDF groups, respectively. The SALDRS rate was lower in the TDR group than in the ACDF group, but no statistical difference was observed (RR 0.25, 95\% CI 


\begin{tabular}{|c|c|c|c|c|c|c|c|c|c|}
\hline Study or Subgroup & $\begin{array}{l}\text { TDR } \\
\text { Events } \\
\end{array}$ & Total & $\begin{array}{l}\text { ACD } \\
\text { Events }\end{array}$ & F Total & Weight & $\begin{array}{l}\text { Risk Ratio } \\
\text { M-H, Fixed, } 95 \% \mathrm{Cl} \\
\end{array}$ & $\begin{array}{r}\text { Risk } \\
\text { M-H, Fixe }\end{array}$ & $\begin{array}{l}\text { Ratio } \\
\text { d, } 95 \% \mathrm{Cl}\end{array}$ & \\
\hline Burkus 2010 & 8 & 276 & 13 & 265 & $12.0 \%$ & $0.59[0.25,1.40]$ & $\pi$ & - & \\
\hline Delamarter 2013 & 2 & 103 & 6 & 106 & $5.3 \%$ & $0.34[0.07,1.66]$ & & E & \\
\hline Donk 2017 & 0 & 50 & 5 & 47 & $5.1 \%$ & $0.09[0.00,1.51]$ & $\leftarrow$ & F & \\
\hline Ghobrial 2018b & 22 & 242 & 35 & 221 & $33.0 \%$ & $0.57[0.35,0.95]$ & -- & & \\
\hline Hou 2016 & 1 & 56 & 7 & 51 & $6.6 \%$ & $0.13[0.02,1.02]$ & & & \\
\hline Phillips 2015 & 1 & 218 & 19 & 185 & $18.5 \%$ & $0.04[0.01,0.33]$ & $\longleftarrow$ & & \\
\hline Radcliff $2017 a$ & 4 & 164 & 8 & 81 & $9.7 \%$ & $0.25[0.08,0.80]$ & & & \\
\hline Radcliff 2017b & 10 & 225 & 8 & 105 & $9.8 \%$ & $0.58[0.24,1.44]$ & & - & \\
\hline Total $(95 \% \mathrm{Cl})$ & & 1334 & & 1061 & $100.0 \%$ & $0.38[0.27,0.53]$ & & & \\
\hline Total events & 48 & & 101 & & & & & & \\
\hline \multicolumn{7}{|c|}{$\begin{array}{l}\text { Heterogeneity: } \mathrm{Chi}^{2}=11.47, \mathrm{df}=7(\mathrm{P}=0.12) ; \mathrm{I}^{2}=39 \% \\
\text { Test for overall effect: } Z=5.66(P<0.00001)\end{array}$} & $0.01 \underset{\quad \text { Favours [experimental] }}{0.1}$ & $\begin{array}{c}10 \\
\text { Favours [control] }\end{array}$ & 100 \\
\hline
\end{tabular}

[0.06, 1.12], $p=0.04, I^{2}=68 \%$, Fig. 7). Meanwhile, the heterogeneity was significant. After excluding the study by Phillips et al. [34], the heterogeneity changed to $0 \%$. However, the result remained the same.

Five studies with 737 patients in the TDR group and 505 patients in the ACDF group were included in the meta-analysis of the SALDRS rate of the groups with unrestricted prosthesis. The SALDRS rate of the TDR group was significantly lower than that of the ACDF group (RR 0.44, 95\% CI [0.30, 0.65], $p=0.29, I^{2}=20 \%$, Fig. 8). The heterogeneity was low.

\section{Sensitivity analysis}

The sensitivity analysis demonstrated that when the study by Phillips et al. [34] was excluded, the heterogeneity in all meta-analyses changed to $0 \%$. However, the results of all meta-analyses did not change in comparison to the original results.

\section{Discussion}

Despite satisfactory clinical results following TDR, the question of whether TDR can reduce the incidence of ASD is uncertain [1, 7-9]. Some investigators have conducted meta-analyses to resolve this controversy. However, these reviews were unable to reach a consensus
[10, 18-23]. The reasons why these studies fail to make an agreement might be as follows: First, there was a lack of sufficient mid- and long-term RCTs, and it was not convincible enough to investigate the incidence of ASD in short- and mid-term RCTs. Second, there was a paucity of consensus on how to define ASD even in RCTs. Third, some reviews focused on reoperation; however, it was the fact that ASD was not the only indication for surgery at the adjacent level, since neck pain or revision surgery at the index surgical level might also be considered as such [15-17]. Thus, it is more reasonable to determine the difference in symptomatic ASD between TDR and ACDF by analyzing mid- and long-term RCTs reporting ASD as the indication for subsequent surgery.

In the present study, we searched the RCTs exhaustively and performed a meta-analysis to compare the mid- to long-term postoperative incidence of SALDRS between ACDF and TDR. We found that the overall SALDRS rate of the TDR group was significantly lower than that of the ACDF group after a minimum followup period of 48 months. The heterogeneity was not significant, and the result was reliable. In a meta-analysis, Ren et al. [10] reported that the rate of requiring operation for ASD was not significantly different between patients in the TDR group and the ACDF group; however,

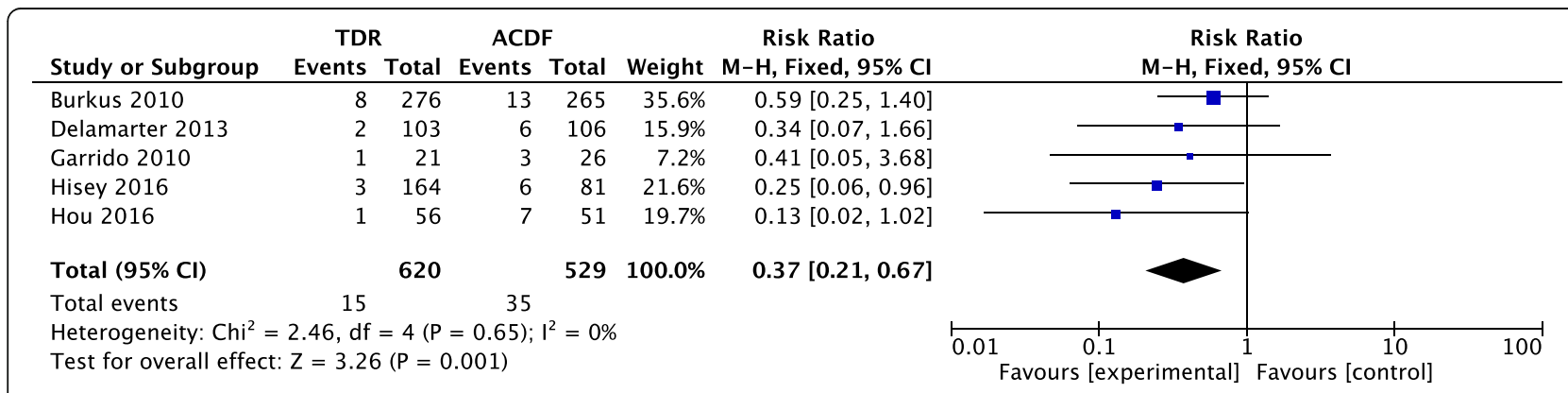

Fig. 4 Forest plot comparing the rate of SALDRS between TDR and ACDF at 4-5 years follow-up. TDR, cervical total disc replacement; ACDF, anterior cervical discectomy and fusion; Cl, confidence interval; df, degrees of freedom; M-H, Mantel-Haenszel 


\begin{tabular}{|c|c|c|c|c|c|c|c|c|c|}
\hline Study or Subgroup & $\begin{array}{c}\text { TDR } \\
\text { Events }\end{array}$ & Total & $\begin{array}{l}\text { ACDF } \\
\text { Events }\end{array}$ & $\begin{array}{l}\mathbf{F} \\
\text { Total } \\
\end{array}$ & Weight & $\begin{array}{c}\text { Risk Ratio } \\
\text { M-H, Random, } 95 \% \mathrm{Cl}\end{array}$ & \multicolumn{3}{|c|}{$\begin{array}{c}\text { Risk Ratio } \\
\text { M-H, Random, 95\% Cl }\end{array}$} \\
\hline Ghobrial 2018b & 36 & 518 & 57 & 486 & $38.5 \%$ & $0.59[0.40,0.88]$ & $-\square$ & & \\
\hline Phillips 2015 & 1 & 218 & 19 & 185 & $11.6 \%$ & $0.04[0.01,0.33]$ & $\longleftarrow$ & & \\
\hline Radcliff 2017a & 4 & 164 & 8 & 81 & $22.3 \%$ & $0.25[0.08,0.80]$ & & & \\
\hline Radcliff $2017 b$ & 10 & 225 & 8 & 105 & $27.6 \%$ & $0.58[0.24,1.44]$ & - & - & \\
\hline Total $(95 \% \mathrm{Cl})$ & & 1125 & & 857 & $100.0 \%$ & $0.36[0.16,0.80]$ & & & \\
\hline Total events & 51 & & 92 & & & & & & \\
\hline $\begin{array}{l}\text { Heterogeneity: } \mathrm{Tau}^{2}= \\
\text { Test for overall effect }\end{array}$ & $\begin{array}{l}0.39 ; C h \\
Z=2.51\end{array}$ & $\begin{array}{l}\mathrm{i}^{2}=8.4 \\
1(\mathrm{P}=0 .\end{array}$ & $\begin{array}{l}40, \mathrm{df}= \\
.01)\end{array}$ & $3(P=$ & $0.04) ; 1^{2}=$ & $=64 \%$ & $0.01 \quad 0.1 \quad 1$ & \begin{tabular}{|cc}
1 & 10 \\
Favours [control]
\end{tabular} & $\overrightarrow{100}$ \\
\hline
\end{tabular}

the result was derived from only 3 RCTs. Due to the lack of studies reporting on ASD as the indication for operation and the small sample size, Zhang et al. [38] reported that the rate of operations at the adjacent level was not significantly different between the TDR and ACDF groups in their meta-analysis. Wu et al. [15] performed a meta-analysis and compared the overall rates of subsequent surgery and rates of subsequent surgery at the operated level and at the adjacent level between patients who underwent ACDF and TDR. They found that patients in the TDR group had a significantly lower rate of reoperation at the operated level and the adjacent level than those in the ACDF group. However, only 3 of 8 studies in the study by $\mathrm{Wu}$ et al. [15] described the reasons for subsequent surgery. Besides, adjacent-level disease was not the only reason for subsequent surgical intervention at the adjacent level. Dong et al. [22] performed a meta-analysis in 2017 and compared adjacent segment reoperation, adjacent segment degeneration, and ASD between patients who underwent ACDF and TDR. They found that the reoperation rate of adjacent levels in the TDR group was significantly lower than that in the ACDF group, and the advantage of TDR in reducing reoperation at the adjacent level increased with increasing follow-up period. However, the difference in ASD between the two groups was not significant. Because of the lack of sufficient RCTs reporting ASD as the indication for operation, neither results of Wu et al. [15] nor Dong et al. [22] were recognized as adequately accurate. The present metaanalysis included a larger number of RCTs reporting ASD as the reason for reoperation; therefore, it is expected to obtain a more accurate and reliable result.

In this meta-analysis, a subgroup analysis with different follow-up periods was performed to investigate the SALDRS rates between the TDR and ACDF groups. The SALDRS rate of the TDR group was significantly lower than that of the ACDF group at $4-5$ years, 7 years, and 9-10 years of follow-up. The heterogeneity was not significant, except for the data on the SALDRS rate at 7 years' follow-up collected from 4 studies. This heterogeneity was derived from the study by Phillips et al. [34], according to the sensitivity analysis. With the exclusion of the study by Phillips et al. [34], the heterogeneity changed to $0 \%$; however, there was no change in the result of the meta-analysis. This is because of their unique patient inclusion criteria, whereby approximately $12 \%$ (29 TDR and 20 ACDF) of the 218 TDR and 185 ACDF patients had prior adjacent or nonadjacent single-level fusions, and the SALDRS rates in the TDR group and ACDF group were different from those of other RCTs.

Although the meta-analysis by $\mathrm{Wu}$ et al. [15] showed that patients in the TDR group had a significantly lower rate of reoperation at the adjacent level than patients in the ACDF group in RCTs of 48-102 months' follow-up, there was no subgroup analysis with different follow-up periods in their study. A total of 8 RCTs reporting SALDRS were enrolled in our meta-analysis, and a subgroup analysis with $4-5$ years, 7 years, and 9-10 years of follow-up was performed for the first time.

\begin{tabular}{|c|c|c|c|c|c|c|c|}
\hline Study or Subgroup & $\begin{array}{c}\text { TDR } \\
\text { Events }\end{array}$ & Total & $\begin{array}{l}\text { ACDF } \\
\text { Events }\end{array}$ & Total & Weight & $\begin{array}{c}\text { Risk Ratio } \\
\text { M-H, Fixed, } 95 \% \mathrm{Cl} \\
\end{array}$ & $\begin{array}{c}\text { Risk Ratio } \\
\text { M-H, Fixed, } 95 \% \mathrm{Cl} \\
\end{array}$ \\
\hline Donk 2017 & 0 & 50 & 5 & 47 & $13.4 \%$ & $0.09[0.00,1.51]$ & 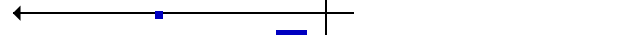 \\
\hline Ghobrial 2018b & 23 & 242 & 35 & 221 & $86.6 \%$ & $0.60[0.37,0.98]$ & \\
\hline Total $(95 \% \mathrm{Cl})$ & & 292 & & 268 & $100.0 \%$ & $0.53[0.33,0.86]$ & \\
\hline Total events & 23 & & 40 & & & & \\
\hline \multicolumn{7}{|c|}{$\begin{array}{l}\text { Heterogeneity: } \mathrm{Chi}^{2}=1.79, \mathrm{df}=1(P=0.18) ; \mathrm{I}^{2}=44 \% \\
\text { Test for overall effect: } Z=2.59(P=0.010)\end{array}$} & $\begin{array}{cccc}0.01 & 0.1 & 1 & 1 \\
& \text { Favours [experimental] } & \text { Favours [control] }\end{array}$ \\
\hline
\end{tabular}




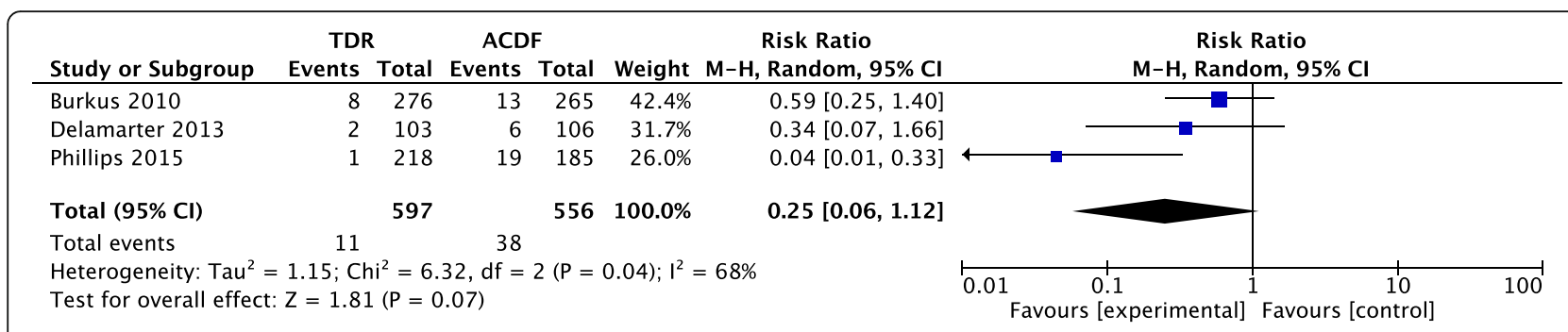

Fig. 7 Forest plot comparing the rate of SALDRS between semi-restricted prosthesis TDR and ACDF. TDR, cervical total disc replacement; ACDF, anterior cervical discectomy and fusion; $\mathrm{Cl}$, confidence interval; $\mathrm{df}$, degrees of freedom; M-H, Mantel-Haenszel

According to previous studies, the different types of prostheses were classified as either unconstrained (Bryan, Mobi-C) or semi-constrained (PCM, PrestigeST, ProDisc-C) [39, 40]. Artificial discs can be categorized as constrained, semi-constrained, and nonconstrained, depending on whether the center of rotation (COR) translates. Constrained implants have a fixed COR, whereas unconstrained implants have a dynamic COR. Semi-constrained implants may have a fixed COR, but there may be coupled translation with rotation [41]. A subgroup analysis was performed for those with unrestricted or semi-restricted prostheses to investigate the SALDRS rate between the TDR and ACDF groups in this meta-analysis. The results showed that the SALDRS rate of the TDR group with semi-restricted prosthesis was lower than that of the ACDF group, but without statistical difference, which might be caused by the small number of included studies and patients (only 3 RCTs). In addition, the results also demonstrated that the SALD RS rate of the TDR group with unrestricted prosthesis was significantly lower than that of the ACDF group, and the heterogeneity was low.

This review has some strengths. First, this is the first meta-analysis to evaluate the SALDRS rates after TDR in comparison to ACDF with a minimum follow-up period of 48 months. Second, only RCTs were included in our study. Third, the subgroup analysis by different follow-up periods and different prosthesis designs guarantees consistency and accuracy.
However, the current study also has some limitations influencing its validity. Firstly, only 9 articles were included in this meta-analysis. Since most RCTs comparing TDR and ACDF were designed as non-inferiority studies, the number of RCTs focusing on SALDRS was limited. In the future, more relevant RCTs are needed. Secondly, although the included articles were considered to have a low risk of bias, most studies showed a high risk of bias in incomplete outcome data, and a follow-up rate of over $80 \%$ in both groups was observed in only two studies. A review of the literature demonstrated that RCTs investigating the SALDRS rates were insufficient. Therefore, more RCTs focusing on SALDRS with longer-term follow-up are warranted.

\section{Conclusions}

Our study showed that the SALDRS rates of the TDR group were significantly lower than those of the ACDF group at 48-120 months' follow-up and at different follow-up periods, and the SALDRS rate of the TDR group with unrestricted prosthesis was significantly lower than that of the ACDF group. However, the SALD RS rate of the TDR group with semi-restricted prosthesis was lower than that of the ACDF group, without statistical difference, which may be attributed to the small number of included studies and patients. Hence, more high-quality RCTs with longer-term follow-up are required to achieve a better comparative analysis of the SALDRS rate after TDR and ACDF.

\begin{tabular}{|c|c|c|c|c|c|c|c|c|c|}
\hline Study or Subgroup & \multicolumn{2}{|c|}{ TDR } & ACDF & F Total & Weight & \multirow{2}{*}{$\begin{array}{c}\begin{array}{c}\text { Risk Ratio } \\
\text { M-H, Fixed, 95\% Cl }\end{array} \\
0.09[0.00,1.51]\end{array}$} & \multicolumn{3}{|c|}{$\begin{array}{c}\text { Risk Ratio } \\
\text { M-H, Fixed, 95\% CI }\end{array}$} \\
\hline Donk 2017 & 0 & 50 & 5 & 47 & $8.0 \%$ & & $\leftarrow$ & $F$ & \\
\hline Ghobrial 2018b & 22 & 242 & 35 & 221 & $51.4 \%$ & $0.57[0.35,0.95]$ & $\neg$ & & \\
\hline Hou 2016 & 1 & 56 & 7 & 51 & $10.3 \%$ & $0.13[0.02,1.02]$ & & & \\
\hline Radcliff 2017a & 4 & 164 & 8 & 81 & $15.0 \%$ & $0.25[0.08,0.80]$ & 7 & & \\
\hline Radcliff $2017 b$ & 10 & 225 & 8 & 105 & $15.3 \%$ & $0.58[0.24,1.44]$ & 7 & - & \\
\hline Total $(95 \% \mathrm{Cl})$ & & 737 & & 505 & $100.0 \%$ & $0.44[0.30,0.65]$ & & & \\
\hline \multirow{2}{*}{\multicolumn{7}{|c|}{$\begin{array}{l}\text { Heterogeneity: } \mathrm{Chi}^{2}=4.97, \mathrm{df}=4(\mathrm{P}=0.29) ; \mathrm{I}^{2}=20 \% \\
\text { Test for overall effect: } Z=4.11(\mathrm{P}<0.0001)\end{array}$}} & & & \\
\hline & & & & & & & 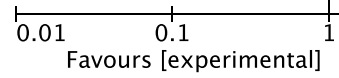 & $\begin{array}{cc}10 \\
\text { Favours [control] }\end{array}$ & $\overrightarrow{100}$ \\
\hline
\end{tabular}




\section{Abbreviations}

ACDF: Anterior cervical discectomy and fusion; ASD: Adjacent segment disease; Cl: Confidence interval; COR: Center of rotation; RCT: Randomized controlled trial; RR: Risk ratio; SALDRS: Symptomatic adjacent-level disease requiring surgery; TDR: Total disc replacement

\section{Acknowledgements}

We thank the nursing staffs from our department and the patients enrolled in this study for their supports.

\section{Authors' contributions}

$G L, Y D$, and HL provided the ideas of this study. YD and GL collected the data. $\mathrm{GL}$ and $\mathrm{YD}$ analyzed the data. $\mathrm{HL}, \mathrm{YH}$, and $\mathrm{YM}$ helped with the interpretation of data. $\mathrm{HL}, \mathrm{YH}$, and $\mathrm{YM}$ provided the funding. All authors read and approved the final manuscript.

\section{Funding}

This study was supported by the Sichuan Province Science and Technology Support Program of China (Grant No. 2019YFQ0002 to H Liu, Grant No. 2018 SZ0045 to Y Hong, Grant No.2018SZ0042 to Y Meng).

\section{Availability of data and materials}

Datasets are available from the corresponding author on reasonable request.

\section{Competing interests}

The authors declare that they have no competing interests.

\section{Author details}

'Department of Orthopedic Surgery, West China Hospital, Sichuan University, No. 37 Guo Xue Xiang, Chengdu 610041, Sichuan, China. ${ }^{2}$ Division of Spine Surgery, Department of Orthopedics, Affiliated Hospital of Southwest Medical University, No. 25 Taiping St, Luzhou 646000, Sichuan Province, China. ${ }^{3}$ Department of Anesthesia and Operation Center/West China School of Nursing, West China Hospital, Sichuan University, No. 37 Guo Xue Xiang, Chengdu 610041, Sichuan, China.

\section{Received: 30 June 2020 Accepted: 10 September 2020}

\section{Published online: 12 October 2020}

\section{References}

1. David Kaye I, Hilibrand AS. Adjacent level disease-background and update based on disc replacement data. Curr Rev Musculoskeletal Med. 2017;10: 147-52. https://doi.org/10.1007/s12178-017-9396-5.

2. Pandey PK, Pawar I, Gupta J, Verma RR. Comparison of outcomes of singlelevel anterior cervical discectomy with fusion and single-level artificial cervical disc replacement for single-level cervical degenerative disc disease. Spine. 2017;42:E41-9. https://doi.org/10.1097/BRS.0000000000001696.

3. Chang KE, Pham MH, Hsieh PC. Adjacent segment disease requiring reoperation in cervical total disc arthroplasty: a literature review and update. J Clin Neurosci. 2017;37:20-4. https://doi.org/10.1016/j.jocn.2016.10.047.

4. Eck JC, Humphreys SC, Lim TH, Jeong ST, Kim JG, Hodges SD, et al. Biomechanical study on the effect of cervical spine fusion on adjacent-level intradiscal pressure and segmental motion. Spine. 2002;27:2431-4. https:// doi.org/10.1097/01.BRS.0000031261.66972.B1

5. Hilibrand AS, Carlson GD, Palumbo MA, Jones PK, Bohlman HH. Radiculopathy and myelopathy at segments adjacent to the site of a previous anterior cervical arthrodesis. J Bone Joint Surg Am. 1999;81:519-28. https://doi.org/10.2106/00004623-199904000-00009.

6. Lee JC, Lee $\mathrm{S}-\mathrm{H}$, Peters $\mathrm{C}$, Riew KD. Adjacent segment pathology requiring reoperation after anterior cervical arthrodesis: the influence of smoking, sex, and number of operated levels. Spine. 2015;40:E571-7. https://doi.org/10. 1097/BRS.0000000000000846.

7. Robertson JT, Papadopoulos SM, Traynelis VC. Assessment of adjacentsegment disease in patients treated with cervical fusion or arthroplasty: a prospective 2-year study. J Neurosurg Spine. 2005;3:417-23. https://doi.org/ 10.3171/spi.2005.3.6.0417

8. Jawahar A, Cavanaugh DA, Kerr EJ, Birdsong EM, Nunley PD. Total disc arthroplasty does not affect the incidence of adjacent segment degeneration in cervical spine: results of 93 patients in three prospective randomized clinical trials. Spine J. 2010;10:1043-8. https://doi.org/10.1016/j.spinee.2010.08.014.
9. Gornet MF, Lanman TH, Burkus JK, Hodges SD, McConnell JR, Dryer RF, et al. Cervical disc arthroplasty with the Prestige LP disc versus anterior cervical discectomy and fusion, at 2 levels: results of a prospective, multicenter randomized controlled clinical trial at 24 months. J Neurosurg Spine. 2017; 26:653-67. https://doi.org/10.3171/2016.10.SPINE16264.

10. Ren C, Song Y, Xue Y, Yang X. Mid- to long-term outcomes after cervical disc arthroplasty compared with anterior discectomy and fusion: a systematic review and meta-analysis of randomized controlled trials. Euro. Spine J. 2014;23:1115-23. https://doi.org/10.1371/journal.pone.0149312..

11. Burkus JK, Traynelis VC, Haid RW, Mummaneni PV. Clinical and radiographic analysis of an artificial cervical disc: 7-year follow-up from the Prestige prospective randomized controlled clinical trial. J Neurosurg Spine. 2014;21: 516-28. https://doi.org/10.3171/2014.6.SPINE13996.

12. Gornet MF, Burkus JK, Shaffrey ME, Nian H, Harrell FE. Cervical disc arthroplasty with Prestige LP disc versus anterior cervical discectomy and fusion: seven-year outcomes. Int J Spine Surg. 2016;10:24. https://doi.org/10. 14444/3024..

13. Janssen ME, Zigler JE, Spivak JM, Delamarter RB, Darden BV, Kopjar B. ProDisc-C total disc replacement versus anterior cervical discectomy and fusion for single-level symptomatic cervical disc disease: seven-year followup of the prospective randomized U.S. Food and Drug Administration Investigational Device Exemption study. J Bone Joint Surg Am. 2015;97: 1738-47. https://doi.org/10.2106/JBJS.N.01186.

14. Shriver MF, Lubelski D, Sharma AM, Steinmetz MP, Benzel EC, Mroz TE. Adjacent segment degeneration and disease following cervical arthroplasty: a systematic review and meta-analysis. Spine J. 2016;16:168-81. https://doi. org/10.1016/j.spinee.2015.10.032.

15. Wu TK, Liu H, Wang BY, Meng Y. Minimum four-year subsequent surgery rates of cervical disc replacement versus fusion: a meta-analysis of prospective randomized clinical trials. Orthop Traumatol Surg Res. 2017;103: 45-51. https://doi.org/10.1016/j.otsr.2016.10.008.

16. Blumenthal SL, Ohnmeiss DD, Guyer RD, Zigler JE. Reoperations in cervical total disc replacement compared with anterior cervical fusion. Spine. 2013; 38(14):1177-82. https://doi.org/10.1097/BRS.0b013e31828ce774.

17. van Eck CF, Regan C, Donaldson WF, Kang JD, Lee JY. The revision rate and occurrence of adjacent segment disease after anterior cervical discectomy and fusion: a study of 672 consecutive patients. Spine. 2014;39(26):2143-7. https://doi.org/10.1097/BRS.0000000000000636.

18. Zhu Y, Zhang B, Liu H, Wu Y, Zhu Q. Cervical disc arthroplasty versus anterior cervical discectomy and fusion for incidence of symptomatic adjacent segment disease: a meta-analysis of prospective randomized controlled trials. Spine (Phila Pa 1976). 2016;41:1493-502. https://doi.org/10, 1097/BRS.0000000000001537.

19. Yang B, Li H, Zhang T, He X, Xu S. The incidence of adjacent segment degeneration after cervical disc arthroplasty (CDA): a meta analysis of randomized controlled trials. PLoS One. 2012;7:e35032. https://doi.org/10. 1371/journal.pone.0035032.

20. Verma K, Gandhi SD, Maltenfort M, Albert TJ, Hilibrand AS, Vaccaro AR, et al. Rate of adjacent segment disease in cervical disc arthroplasty versus singlelevel fusion: meta-analysis of prospective studies. Spine. 2013;38:2253-7. https://doi.org/10.1097/BRS.0000000000000052..

21. Luo J, Gong M, Huang S, Yu T, Zou X. Incidence of adjacent segment degeneration in cervical disc arthroplasty versus anterior cervical decompression and fusion meta-analysis of prospective studies. Arch Orthop Trauma Surg. 2014;135:155-60. https://doi.org/10.1007/s00402-014-2125-2.

22. Dong L, Xu Z, Chen X, Wang D, Li D, Liu T, et al. The change of adjacent segment after cervical disc arthroplasty compared with anterior cervical discectomy and fusion: a meta-analysis of randomized controlled trials. Spine J. 2017;17:1549-58. https://doi.org/10.1016/j.spinee.2017.06.010.

23. Zhong ZM, Zhu SY, Zhuang JS, Wu Q, Chen JT. Reoperation after cervical disc arthroplasty versus anterior cervical discectomy and fusion: a metaanalysis. Clin Orthop Relat Res. 2016;474:1307-16. https://doi.org/10.1007/ s11999-016-4707-5.

24. Moher D, Liberati A, Tetzlaff J, Altman DG. Preferred reporting items for systematic reviews and meta-analyses: the PRISMA statement. Int I Surg. 2010;8:336-41. https://doi.org/10.1016/j.jisu.2010.02.007..

25. Furlan AD, Pennick V, Bombardier C, van Tulder M. 2009 updated method guidelines for systematic reviews in the Cochrane Back Review Group. Spine. 2009;34(18):1929-41. https://doi.org/10.1097/BRS.0b013e3181b1c99f.

26. Garrido BJ, Taha TA, Sasso RC. Clinical outcomes of bryan cervical disc arthroplasty a prospective, randomized, controlled, single site trial with 48- 
month follow-up. J Spinal Disord Tech. 2010;23:367-71. https://doi.org/10. 1097/BSD.0b013e3181bb8568.

27. Hisey MS, Bae HW, Davis RJ, Gaede S, Hoffman G, Kim KD, et al. Prospective, Randomized comparison of cervical total disk replacement versus anterior cervical fusion: results at 48 months follow-up. J Spinal Disord Tech. 2015;28: E237-43. https://doi.org/10.1097/BSD.0000000000000185.

28. Zhang HX, Shao YD, Chen Y, Hou Y, Cheng L, Si M, et al. A prospective, randomised, controlled multicentre study comparing cervical disc replacement with anterior cervical decompression and fusion. Int Orthop. 2014;38:2533-41. https://doi.org/10.1007/s00264-014-2497-5.

29. Delamarter RB, Zigler J. Five-year reoperation rates, cervical total disc replacement versus fusion, results of a prospective randomized clinical trial. Spine. 2013;38:711-7. https://doi.org/10.1097/BRS.0b013e3182797592.

30. Burkus JK, Haid RW, Traynelis VC, Mummaneni PVA. long-term clinical and radiographic outcomes of cervical disc replacement with the Prestige disc: results from a prospective randomized controlled clinical trial. J Neurosurg Spine. 2010;13:308-18. https://doi.org/10.3171/2010.3.SPINE09513.

31. Hisey MS, Zigler JE, Jackson R, Nunley PD, Bae HW, Kim KD, et al. Prospective, randomized comparison of one-level mobi-c cervical total disc replacement vs anterior cervical discectomy and fusion: results at 5-year follow-up. Int J Spine Surg. 2016;10. https://doi.org/10.14444/3010.

32. Hou Y, Nie L, Pan X, Si M, Han Y, Li J, et al. Effectiveness and safety of Mobi$C$ for treatment of single-level cervical disc spondylosis: a randomised control trial with a minimum of five years of follow-up. Bone Jnt J. 2016;98B(6):829-33. https://doi.org/10.1302/0301-620X.98B6.36381.

33. Jackson RJ, Davis RJ, Hoffman GA, Bae HW, Hisey MS, Kim KD, et al. Subsequent surgery rates after cervical total disc replacement using a MobiC cervical disc prosthesis versus anterior cervical discectomy and fusion: a prospective randomized clinical trial with 5-year follow-up. J Neurosurg Spine. 2016;24:734-45. https://doi.org/10.3171/2015.8.SPINE15219..

34. Phillips FM, Geisler FH, Gilder KM, Reah C, Howell KM, McAfee PC. Longterm outcomes of the US FDA IDE prospective, randomized controlled clinical trial comparing PCM cervical disc arthroplasty with anterior cervical discectomy and fusion. Spine. 2015;40:674-83. https://doi.org/10.1097/BRS. 0000000000000869.

35. Radcliff K, Davis RJ, Hisey MS, Nunley PD, Hoffman GA, Jackson RJ, et al. Long-term evaluation of cervical disc arthroplasty with the Mobi-C(c) cervical disc: a randomized, prospective, multicenter clinical trial with sevenyear follow-up. Int J Spine Surg. 2017;11:31. https://doi.org/10.14444/4031.

36. Ghobrial GM, Lavelle WF, Florman JE, Riew KD, Levi AD. Symptomatic adjacent level disease requiring surgery: analysis of 10-year results from a prospective, randomized, clinical trial comparing cervical disc arthroplasty to anterior cervical fusion. Neurosurgery. 2019;84:347-54. https://doi.org/10. 1093/neuros/nyy118.

37. Donk RD, Verbeek ALM, Verhagen WIM, Groenewoud H, Hosman AJF, Bartels R. What's the best surgical treatment for patients with cervical radiculopathy due to single-level degenerative disease? A randomized controlled trial. PLoS One. 2017;12:e0183603. https://doi.org/10.1371/journal. pone. 0183603 .

38. Zhang Y, Liang C, Tao Y, Zhou X, Li H, Li F, et al. Cervical total disc replacement is superior to anterior cervical decompression and fusion: a meta-analysis of prospective randomized controlled trials. PLoS One. 2015: 10:e0117826. https://doi.org/10.1371/journal.pone.0117826.

39. Lin CY, Kang H, Rouleau JP, Hollister SJ, Marca FL. Stress analysis of the interface between cervical vertebrae end plates and the Bryan, Prestige LP, and ProDisc-C cervical disc prostheses: an in vivo image-based finite element study. Spine. 2009;34:1554-60. https://doi.org/10.1097/BRS. Ob013e3181aa643b.

40. Park SB, Kim KJ, Jin YJ, Kim HJ, Jahng TA, Chung CK. X-Ray-based kinematic analysis of cervical spine according to prosthesis designs: analysis of the Mobi-C, Bryan, PCM, and Prestige LP. J Spinal Disord Tech. 2015;28:E291-7. https://doi.org/10.1097/BSD.0b013e318288a923.

41. Choi H, Baisden JL, Yoganandan N. A comparative in vivo study of semiconstrained and unconstrained cervical artificial disc prostheses. Mil Med. 2019;184:637-43. https://doi.org/10.1093/milmed/usy395.

\section{Publisher's Note}

Springer Nature remains neutral with regard to jurisdictional claims in published maps and institutional affiliations.

\section{Ready to submit your research? Choose BMC and benefit from}

- fast, convenient online submission

- thorough peer review by experienced researchers in your field

- rapid publication on acceptance

- support for research data, including large and complex data types

- gold Open Access which fosters wider collaboration and increased citations

- maximum visibility for your research: over $100 \mathrm{M}$ website views per year

At BMC, research is always in progress.

Learn more biomedcentral.com/submissions 